\title{
Behavioral Variables Associated with Obesity in Police Officers
}

\author{
S. Hakan CAN ${ }^{1 *}$ and Helen M. HENDY ${ }^{2}$ \\ ${ }^{1}$ Administration of Justice Program, Penn State University, USA \\ ${ }^{2}$ Psychology Program, Penn State University, USA \\ Received December 24, 2013 and accepted February 13, 2014 \\ Published online in J-STAGE April 2, 2014
}

\begin{abstract}
Past research has documented that non-behavioral variables (such as long work hours, exposure to police stressors) are associated with obesity risk in police officers, but limited research has examined behavioral variables that might be targeted by Employee Assistance Programs for police weight management. The present study compared non-obese and obese officers for behavioral variables found associated with obesity in other adult samples: physical activity (cardiovascular, strength-training, stretching), sleep duration, and consumption of alcohol, fruit and vegetables, and snack foods. Participants included 172 male police officers who completed questionnaires to report height and weight, used to calculate body mass index $\left(B M I=\mathrm{kg} / \mathrm{m}^{2}\right)$ and to divide them into "nonobese" and "obese" groups. They also reported the above behaviors and six non-behavioral variables found associated with obesity risk: age, health problems, family support, police work hours, police stressors, police support. ANCOVAs compared each behavioral variable across obesity status (non-obese, obese), with the six non-behavioral variables used as covariates. Results revealed that cardiovascular and strength-training physical activity were the only behavioral variables that differed significantly between non-obese and obese police officers. The use of self-reported height and weight values may provide Employee Assistance Program with improved cost, time, and officer participation.
\end{abstract}

Key words: Police obesity, Weight management, Physical activity, Employee Assistance Programs

\section{Behavioral Variables Associated with Obesity in Police Officers}

The physical challenges of police work may include everyday activities such as walking, climbing stairs, bending, and lifting ${ }^{1)}$ as well as critical incident activities such as chasing suspects and violent confrontations ${ }^{2)}$. Although the physical requirements of police work suggest the importance of maintaining a healthy weight status, recent research suggests that $40.5 \%$ of American police officers

*To whom correspondence should be addressed. E-mail: hakancan@psu.edu

(C)2014 National Institute of Occupational Safety and Health are obese ${ }^{3)}$,which is a prevalence rate above the national average of $35.5 \%$ for adult men and $35.8 \%$ for adult women ${ }^{4)}$. Other research has examined behavioral variables associated with police weight status, most often with a focus on sleep problems ${ }^{5,6)}$. Research with other adult samples suggests that additional behavioral variables associated with obesity risk for police officers would include physical activity, consumption of low-calorie fruits and vegetables, infrequent consumption of high-calorie snack foods, and consumption of alcohol ${ }^{7-9)}$. To identify behavioral variables most associated with obesity risk in police officers, other non-behavioral variables should also be taken into account. For example, past research with police officers suggests that these non-behavioral factors may 
include long work hours ${ }^{10)}$, exposure to police stressors ${ }^{3 \text {, }}$ ${ }^{10)}$, and perceived police support ${ }^{11)}$. Research with other adult samples suggests that additional non-behavioral variables associated with obesity risk would include older age, health problems, and poor family support ${ }^{12-16)}$.

\section{Purpose of the present study}

Because past research often finds gender differences in how non-behavioral variables are associated with obesity in police officers $^{3,11)}$, the present study focuses only on male police officers. A recent review of weight management interventions for adult males recommended workplace programs that targeted specific behaviors and used self-monitoring procedures ${ }^{9}$. The benefit of identifying specific behaviors most associated with obesity risk for police officers is that these behaviors could be targeted by such workplace Employee Assistance Programs for police weight management. The present study offers the first available examination of seven behavioral variables for their association with obesity in male police officers: physical activity (measured separately as cardiovascular activity, strength-training, and stretching), sleep duration, and consumption of alcohol, fruit and vegetables (FV), and snack foods high in fat, sugar, or salt. For greater clarity of the associations between these seven behaviors and obesity status in police officers, the planned analyses controlled for six non-behavioral variables also expected to be associated with obesity risk from past research (age, health, family support, work hours, police stressors, police support).

Besides evaluation of six specific behaviors for their association with obesity status in police officers, another new feature of the present study is that, as recommended by Taylor and colleagues ${ }^{9}$, it uses officer self-reported values of height and weight to determine BMI scores and obesity status. Recent research with adolescents suggests that self-reported height and weight values show acceptable test-retest reliability and concurrent validity with values measured by trained personnel ${ }^{17)}$. Even with some expected inaccuracy of measurement when using self-reported height and weight, this procedure offers the advantages of saving time and cost for police departments reluctant to interrupt police work, ask officers to strip down to minimal clothing, and pay trained personnel to measure them.

\section{Method}

\section{Participants}

Study participants were identified from a larger sample of 276 police officers from 18 Pennsylvania police departments with a minimum of five sworn officers ( 256 men, 20 women; 90\% Caucasian; 69\% married; 51\% Patrol officer rank; mean age $=41.2 \mathrm{yr}, \mathrm{SD}=9.3$; mean years of service $=15.6, \mathrm{SD}=8.4$ ). These 276 officers represented a response rate of $78.6 \%$ after three reminders to the departments. Because of the small percentage of female officers in the total sample, and because male and female officers may differ in variables associated with overweight ${ }^{3,9)}$, the focus of the present study was the 247 (96.5\%) of male officers who provided height and weight information for determination of BMI $\mathrm{kg} / \mathrm{m}^{2}$ scores, with $172(70 \%)$ of them also providing information for other behavioral and nonbehavioral variables considered in the present study $(90 \%$ Caucasian; 68\% married; 55\% Patrol officer rank; mean age $=40.0 \mathrm{yr}, \mathrm{SD}=8.8 ;$ mean years of service $=14.5, \mathrm{SD}$ $=8.3$ ). Of this final subset of 172 male police officers, 100 were "non-obese" with BMI score under $30 \mathrm{~kg} / \mathrm{m}^{2}$ and 72 were "obese" with BMI $\mathrm{kg} / \mathrm{m}^{2}$ scores $30 \mathrm{~kg} / \mathrm{m}^{2}$ and above.

\section{Procedures}

After approval by the Institutional Review Board of Penn State University on April 30, 2012, anonymous questionnaires were distributed to police officers in the format requested by their departments. The two questionnaire formats offered were paper copies that could be sealed in large envelopes and returned with postage provided, or online copies using Survey Methods and the Pennsylvania Chief of Police Association Listserve. The 10-page questionnaire requested demographic information (including height in inches and weight in pounds to be used to determine their obesity status), seven behavioral variables that might be associated with police obesity (cardiovascular physical activity, strength-training, stretching, sleep duration, and consumption of alcohol, fruit and vegetables, and snack foods), and six other non-behavioral variables that might be associated with obesity risk (age, health problems, family support, work hours, police stressors, and police support).

\section{Measurement of obesity status}

The officers' height in inches was converted to meters, their weight in pounds was converted to kilograms, and their body mass index (BMI $\mathrm{kg} / \mathrm{m}^{2}$ ) was calculated as kilograms/meters ${ }^{2)}$. "Non-obese" officers were those with 
BMI $\mathrm{kg} / \mathrm{m}^{2}$ scores less than 30 , and "obese" officers were those with BMI scores 30 and above $\mathrm{e}^{4)}$.

\section{Measurement of behavioral variables that might be associated with police obesity}

Physical activity in minutes/week was measured separately for cardiovascular activity, strength-training, and stretching. Officers were asked to report their "typical number of minutes of cardiovascular exercise .... strengthtraining exercise .... stretching exercise" separately for each day of the week (Monday, Tuesday, Wednesday, Thursday, Friday, Saturday, Sunday). Minutes were summed across the seven days of the week separately for each three types of physical activity. Sleep duration in hour/week was were measured by asking officers to report their usual sleep hours for each day of the week, with the sum of sleep minutes across seven days used as their sleep score. Alcohol consumption in drinks/week was measured by asking officers to report their typical number of drinks for each day of the week (with one "drink" = 12 ounces beer, 5 ounces wine, shot glass of spirits), with the number of drinks summed across seven days used as their alcohol score. Consumption of fruits and vegetables (FV) and consumption of snack foods in servings/day were measured with a food frequency questionnaire ${ }^{18)}$ for which officers used five-point ratings $(1=$ never, $2=$ once or twice in the week, $3=$ three or more times in the week, $4=$ once or twice per day, $5=$ three or more times per day) to indicate how often during the past week they ate each of 123 foods including $51 \mathrm{FV}$ and 10 snack foods (chocolate, other candy, cookies or brownies, donuts or pastry, cake or pie, popcorn, salty chips, pretzels, ice cream, pudding). The ratings for FV and snack foods were converted to estimates of daily servings $(1=0 / 7 \mathrm{~d}=0.000,2=1 / 7 \mathrm{~d}=$ $0.143,3=3 / 7 \mathrm{~d}=0.429,4=7 / 7 \mathrm{~d}=1.00,5=21 / 7 \mathrm{~d}=3.00$ ), with the sum of daily servings calculated for the set of 51 FV and the set of 10 snack foods. Because of the tendency to over-report consumption of items on food frequency lists ${ }^{18)}$, the total for each food group was truncated to 7 daily servings.

\section{Measurement of non-behavioral control variables}

Non-behavioral variables included as covariates in the present study included age, health problems, work hours, work stressors, and family and police social support because of past research documenting associations of these variables with obesity risk ${ }^{3,10,11,13-16)}$. Age was selfreported in the demographic variables asked of officers. Health problems were measured with a 16 -item scale ${ }^{19}$ ) that included complaints in a number of body systems such as chest pains, breathlessness, headaches, dizziness, numbness, nausea, sore muscles, weakness, constipation, ulcers. Officers were asked to use a five-point rating ( $1=$ never, $2=$ rarely, $3=$ sometimes, $4=$ often, $5=$ always) to report how much they were bothered by each health problem during the past year, with the sum of ratings used as their health problems score. Family support was measured by asking officers to use a five-point rating ( $1=$ never, 2 = rarely, $3=$ sometimes, $4=$ often, $5=$ always) to respond to the 23-item family subscale of the Family and Friend Social Support Scale ${ }^{20)}$. Appropriate items were reversed, and then the mean of the 23 ratings was the family support score. Police work hours were measured by asking officers to report the "number of hours per week you presently work as a police officer." Police stressors were measured with the 25-item Law Enforcement Officer Stress Survey (LEOSS) ${ }^{21)}$. The LEOSS lists a variety of stressful scenarios possible for police officers including critical incidents, departmental politics, and home-work conflicts. Officers were asked to use five-point ratings to report both the "likelihood" and the "difficulty" of each scenario, with the product of these two ratings being the score for each item, with the sum of these product scores calculated as the overall police stressors score. Police support was measured with the same 23-item Family and Friend Social Support Scale ${ }^{20)}$ as that used to measure family support, and using similar scoring procedures.

\section{Data analysis}

SPSS 19.0 was used for all analyses of the present study. Descriptive statistics were calculated for demographic and study variables for the 100 non-obese and 72 obese police officers of the present study (Table 1). $\chi^{2}$ analyses or $t$ tests were used to determine whether these 172 officers who completed the study variables differed significantly in demographics (age, ethnicity, marital status, education, police rank, years of service) from the 75 officers who did not report all study variables.

To examine how police officer weight was associated with specific behavioral variables, simple bivariate correlations were calculated between BMI scores and seven behavioral variables for the 172 police officers: cardiovascular activity, strength-training, stretching, sleep duration, and consumption of alcohol, FV, and snack foods (Table 2). In addition, one-way analysis of covariances (ANCOVAs) were used separately for each of the seven behavioral variables to compare them across officer obesity status (non-obese, obese), with covariates being six 
Table 1. Descriptive statistics for non-obese $(n=100)$ and obese $(n=72)$ male police officers for behavioral variables studied for association with obesity, and non-behavioral variables considered as control variables in ANCOVAs of the present study

\begin{tabular}{lcc}
\hline Variable & $\begin{array}{c}\text { Non-Obese } \\
\text { Mean (SD) }\end{array}$ & $\begin{array}{c}\text { Obese } \\
\text { Mean (SD) }\end{array}$ \\
\hline Behavioral variables & & \\
$\quad$ Physical activity & & \\
$\quad$ Cardiovascular (min/wk) & $167.3(136.8)$ & $92.1(98.6)$ \\
$\quad$ Strength-training (min/wk) & $136.9(152.5)$ & $71.2(118.4)$ \\
$\quad$ Stretching (min/wk) & $32.6(50.6)$ & $19.8(33.8)$ \\
Sleep (h/wk) & $44.7(7.2)$ & $44.2(8.0)$ \\
FV consumption (servings/d) & $3.9(1.9)$ & $3.5(2.2)$ \\
Snack-food consumption (servings/d) & $1.0(1.2)$ & $1.0(0.9)$ \\
Alcohol consumption (drinks/wk) & $6.4(10.7)$ & $6.0(8.3)$ \\
Non-behavioral control variables & & \\
Age & $40.1(9.0)$ & $39.9(8.5)$ \\
Health problems & $26.6(2.2)$ & $25.0(6.3)$ \\
Family support & $4.0(0.7)$ & $3.9(0.7)$ \\
Police work hours (per wk) & $45.1(10.4)$ & $45.5(10.9)$ \\
Police stressors & $139.0(8.4)$ & $138.3(90.6)$ \\
Police support & $3.3(0.6)$ & $3.4(0.6)$ \\
\hline
\end{tabular}

Table 2. Bivariate correlations between BMI scores $\left(\mathrm{kg} / \mathrm{m}^{2}\right)$ and seven behavioral variables for 172 police officers: cardiovascular physical activity $(\mathrm{min} / \mathrm{wk})$, strength-training ( $\mathrm{min} / \mathrm{wk})$, stretching (min/ wk), sleep (h/wk), alcohol consumption (drinks/wk), fv consumption (servings/d), snack-food consumption (servings/d)

\begin{tabular}{|c|c|c|c|c|c|c|c|c|}
\hline & BMI & Cardio & Strength & Stretch & Sleep & Alcohol & FV & Snacks \\
\hline BMI & $\mathrm{X}$ & $-0.301 * * *$ & $-0.216^{* *}$ & -0.148 & 0.062 & -0.026 & -0.064 & -0.016 \\
\hline Cardio & & X & $0.362 * * *$ & $0.396 * * *$ & 0.046 & -0.022 & $0.201^{* *}$ & 0.079 \\
\hline Strength & & & $\mathrm{X}$ & $0.301 * * *$ & 0.049 & 0.031 & $0.175^{*}$ & -0.029 \\
\hline Stretch & & & & $\mathrm{X}$ & 0.088 & -0.085 & $0.151^{*}$ & 0.060 \\
\hline Sleep & & & & & $\mathrm{X}$ & 0.029 & -0.080 & -0.028 \\
\hline Alcohol & & & & & & $\mathrm{X}$ & -0.114 & $0.223 * *$ \\
\hline FV & & & & & & & $X$ & 0.260 ** \\
\hline Snacks & & & & & & & & $\mathrm{X}$ \\
\hline
\end{tabular}

$* p<0.05, * * p<0.01, * * * p<0.001$.

non-behavioral variables selected because past research with police and other adult samples suggests they may be related to weight status ${ }^{3,10,11,13-16)}$-age, health problems, family support, police work hours, police stressors, and police support (Table 3). ANCOVA was chosen because of its robustness in detecting variable associations even when the variables have distributions that depart from a normal distribution $^{22)}$ as expected for some behavioral variables included in the present study (such as physical activity and alcohol consumption) with skewed distributions in which most participants report low scores and a few report very high scores.

\section{Results}

Differences between officers who did and did not report all study variables

$\chi^{2}$ analyses revealed that the 172 officers who provided all study variables differed from the 75 officers who did not by showing lower percentages of obesity $(41.9 \%$ vs. $57.3 \% ; p=0.025$ ), lower percentages of being married ( $68 \%$ vs. $84 \%$; $p=0.021)$, and higher percentages of being Patrol Officer rank ( $55 \%$ vs. $39 \%$; $p=0.024)$. Officers who did and did not report all study variables did not differ significantly in their percentages of being Caucasian $(p=0.930)$ 
Table 3. ANCOVA results comparing obese and non-obese officers for seven behaviors (cardiovascular activity, strength-training, stretching, sleep, alcohol, fv, snack-foods), with six non-behavioral variables as covariates

\begin{tabular}{|c|c|c|c|c|c|c|}
\hline & Effect & $\mathrm{F}$ & $\mathrm{df}$ & $p<$ & $\begin{array}{l}\text { partial Eta } \\
\text { effect size }\end{array}$ & SE \\
\hline \multirow[t]{7}{*}{ Cardiovascular } & Obesity (no/yes) & 14.33 & $(1,159)$ & $0.001 *$ & 0.083 & 19.52 \\
\hline & Age & 0.01 & & & & \\
\hline & Health problems & 0.02 & & & & \\
\hline & Family support & 2.12 & & & & \\
\hline & Police work hours & 0.15 & & & & \\
\hline & Police stressors & 0.25 & & & & \\
\hline & Police support & 1.57 & & & & \\
\hline \multirow[t]{7}{*}{ Strength-train } & Obesity (no/yes) & 8.11 & $(1,155)$ & $0.01 *$ & 0.050 & 22.02 \\
\hline & Age & 6.86 & & & & \\
\hline & Health problems & 0.52 & & & & \\
\hline & Family support & 0.86 & & & & \\
\hline & Police work hours & 0.20 & & & & \\
\hline & Police stressors & 0.14 & & & & \\
\hline & Police support & 0.06 & & & & \\
\hline \multirow[t]{7}{*}{ Stretching } & Obesity (no/yes) & 3.09 & $(1,162)$ & $0.090(\mathrm{~ns})$ & 0.019 & 6.87 \\
\hline & Age & 0.82 & & & & \\
\hline & Health problems & 0.00 & & & & \\
\hline & Family support & 7.59 & & & & \\
\hline & Police work hours & 0.16 & & & & \\
\hline & Police stressors & 0.03 & & & & \\
\hline & Police support & 2.94 & & & & \\
\hline \multirow[t]{7}{*}{ Sleep } & Obesity (no/yes) & 0.06 & $(1,163)$ & $0.820(\mathrm{~ns})$ & 0.000 & 1.07 \\
\hline & Age & 5.29 & & & & \\
\hline & Health problems & 0.00 & & & & \\
\hline & Family support & 0.00 & & & & \\
\hline & Police work hours & 17.10 & & & & \\
\hline & Police stressors & 14.70 & & & & \\
\hline & Police support & 0.67 & & & & \\
\hline \multirow[t]{7}{*}{ Alcohol } & Obesity (no/yes) & 0.21 & $(1,160)$ & $0.650(\mathrm{~ns})$ & 0.001 & 1.51 \\
\hline & Age & 5.49 & & & & \\
\hline & Health problems & 1.76 & & & & \\
\hline & Family support & 4.32 & & & & \\
\hline & Police work hours & 1.57 & & & & \\
\hline & Police stressors & 0.00 & & & & \\
\hline & Police support & 0.32 & & & & \\
\hline \multirow[t]{7}{*}{ Fruit and vegetable } & Obesity (no/yes) & 2.07 & $(1,164)$ & $0.160(\mathrm{~ns})$ & 0.012 & 0.30 \\
\hline & Age & 0.01 & & & & \\
\hline & Health problems & 2.63 & & & & \\
\hline & Family support & 4.91 & & & & \\
\hline & Police work hours & 5.93 & & & & \\
\hline & Police stressors & 0.98 & & & & \\
\hline & Police support & 2.64 & & & & \\
\hline \multirow[t]{7}{*}{ Snack-foods } & Obesity (no/yes) & 0.07 & $(1,164)$ & $0.800(\mathrm{~ns})$ & 0.000 & 0.17 \\
\hline & Age & 5.54 & & & & \\
\hline & Health problems & 5.82 & & & & \\
\hline & Family support & 0.73 & & & & \\
\hline & Police work hours & 4.41 & & & & \\
\hline & Police stressors & 0.23 & & & & \\
\hline & Police support & 1.45 & & & & \\
\hline
\end{tabular}


or of having a college education ( $p=0.571)$.

T-tests revealed that the 172 officers who provided all study variables differed from the 75 officers who did not by being younger in age (mean $=40.0 \mathrm{yr}, \mathrm{SD}=8.8$; mean $=44.1 \mathrm{yr}, \mathrm{SD}=9.3$; respectively; $p=0.001$ ), with lower BMI scores (mean $=29.4 \mathrm{~kg} / \mathrm{m}^{2}, \mathrm{SD}=4.2$; mean $=31.4, \mathrm{SD}=5.1$; mean $=29.4 \mathrm{~kg} / \mathrm{m}^{2}, \mathrm{SD}=4.2$; respectively; $p=0.001$ ), with fewer $\mathrm{yr}$ of police service (mean = $14.5, \mathrm{SD}=8.3$; mean $=18.2 \mathrm{yr}, \mathrm{SD}=7.7$; respectively; $p=0.001$ ).

\section{Behavioral variables associated with police weight}

Bivariate correlations revealed that of the seven behavioral variables considered, only cardiovascular physical activity (in min/wk) and strength-training (in min/wk) were significantly associated with BMI scores for police officers. More specifically, the more cardiovascular and strength-training activity the officers' reported, the lower their weight status as indicated by BMI scores (Table 2).

Similarly, ANCOVA revealed that when the six nonbehavioral variables were controlled (age, health problems, family support, police work hours, police stressors, police support), only cardiovascular physical activity and strength-training were significantly different between police officers who were obese and those who were not obese, with more of these two types of physical activity reported by officers who were not obese, as seen in Table 1 (Table 3).

\section{Discussion}

Male police officers of the present study showed obesity prevalence rates of $41.9 \%$, which is similar to the $40.5 \%$ obesity rate found for another sample of police officers ${ }^{3)}$, and higher than the $35.5 \%$ rate for U.S. men found by the National Health and Nutrition Examination Survey ${ }^{4}$. Of the seven behavioral variables considered for their association with police obesity in the present study, only cardiovascular and strength-training physical activity was significantly different between non-obese and obese officers, with obese officers reporting fewer minutes/week of both behaviors. These results correspond to those of past studies with other samples of adults in which more physical activity was associated with lower BMI values and reduced risk for obesity ${ }^{7}$.

One unique feature of the present study was that it used self-reported values for the police officers' weight status and behavioral variables. The benefit of such self-reported measures is that they show acceptable reliability and valid- ity $^{17)}$ and have been recommended for workplace weight management programs ${ }^{9}$ because they save time and expense compared to hiring trained personnel to monitor these weight and behavioral variables.

Another unique feature of the present study was that it provides the first examination of how weight status in police officers is associated with a set of behavioral variables found associated with weight status in past studies with police and other adult samples ${ }^{5-9)}$ - physical activity, sleep duration, alcohol, FV, snacks. In addition, the present study considered how physical activity was associated with officer weight status separately for three types of exercise (cardiovascular, strength-training, stretching), which allows Employee Assistance Programs to target behaviors more specifically for police weight management. Results of the present study suggest that such weight management efforts work to increase officers' cardiovascular and strength-training physical activity.

Perhaps Employee Assistance Programs for weight management could work to provide officers with access to departmental equipment for cardiovascular workouts (such as treadmills, exercise bikes, elliptical machines) or strength-training. If departmental space is limited, perhaps they could provide coupons for community gyms, golf courses, bowling alleys, skating rinks, or walking trails. They could be encouraged to form police teams to compete in community softball, basketball, or volleyball tournaments. As departmental funds allow, officers could be offered incentives to increase their physical activity, such as tokens for each hour of participation in physical activity, with tokens later traded for money, extra vacation time, or other rewards valued by officers.

\section{Study limitations}

One limitation of the present study was that it included only self-reported weight status information from police officers, rather than values measured by trained medical personnel. However, recent research with adolescents has documented the reliability and validity of self-reported height and weight values ${ }^{17}$ ) and a recent review of weight interventions for adult males suggests that self-monitoring of height and weight encourages program adherence and effectiveness $^{9}$. In addition, because the use of self-reported measures offers savings in cost and time compared to the use of trained personnel to measure officers, many police departments may choose them to assess obesity risk in their officers and to monitor Employee Assistance Program effectiveness for weight management. Officer participation might also be enhanced by the availability 
of standard scales and tape measures on site at the police department, random validity checks by trained personnel with incentives for weight improvements, and use of an online community for guidance on accurate height and weight measurement and for officer feedback about the program $^{9)}$.

Another limitation of the present study was that $75(30 \%)$ of the 247 officers in the present study who provided weight status information did not complete the questionnaire to give behavioral variables that might have been associated with their obesity risk. The finding that these 75 officers with incomplete information were older, heavier, with more years of service than the 172 officers who completed the questionnaire suggests that older and more experienced police officers may be found to be the most reluctant to participate in Employee Assistance Programs designed to improve weight management.

A third limitation of the present study was that it included only males and mostly Caucasian officers from Pennsylvania. Future research could include samples of both male and female officers that are more ethnically and regionally diverse to see if the patterns found in the present study apply to them as well.

Finally, a limitation of the present study is that its questionnaire methodology only allows conclusions about correlations among variables, but not conclusions about the direction of these variables relationships. For example, did less physical activity cause the officers' weight to increase, or did their increased weight discourage them from exercising? Future research could use more experimental approaches to examine how weight status in police officers changes when they are randomly assigned to control groups or exercise groups.

\section{References}

1) Anderson GS, Plecas D, Segger T (2001) Police officer physical ability testing: re-validating a selection criterion. Policing. Int J Pol Sci Manage 24, 8-31.

2) Weiss DS, Brunet A, Best SR, Metzler TJ, Liberman A, Pole N, Fagan JA, Marmar CR (2010) Frequency and severity approaches to indexing exposure to trauma: the Critical Incident History Questionnaire for police officers. J Trauma Stress 23, 734-43. [Medline] [CrossRef]

3) Hartley TA, Burchfiel CM, Fekedulegn D, Andrew ME, Knox SS, Violanti JM (2011) Associations between police officer stress and the metabolic syndrome. Int J Emerg Ment Health 13, 243-56. [Medline]

4) Flegal KM, Carroll MD, Kit BK, Ogden CL (2012) Prevalence of obesity and trends in the distribution of body mass index among US adults, 1999-2010. JAMA 307,
491-7. [Medline] [CrossRef]

5) Charles LE, Burchfiel CM, Fekedulegn D, Andrew ME, Violanti JM, Vila B (2007) Obesity and sleep: the Buffalo police health study. Policing. Int J Police Str Manage 30, 203-14. [CrossRef]

6) Rajaratnam SMW, Barger LK, Lockley SW, Shea SA, Wang W, Landrigan CP, O'Brien CS, Qadri S, Sullivan JP, Cade BE, Epstein LJ, White DP Czeisler CA, Harvard Work Hours, Health and Safety Group (2011) Sleep disorders, health, and safety in police officers. JAMA 306, 2567-78. [Medline] [CrossRef]

7) Fletcher B, Hanson J, Page N, Pine K (2011) FITdo something different: a new behavioral program for sustained weight loss. Swiss J Psychol 70, 25-34. [CrossRef]

8) Gearhardt AN, Corbin WR (2009) Body mass index and alcohol consumption: family history of alcoholism as a moderator. Psychol Addict Behav 23, 216-25. [Medline] [CrossRef]

9) Taylor PJ, Kolt GS, Vandelanotte C, Caperchione CM, Mummery WK, George ES, Karunanithi M, Noakes MJ (2013) A review of the nature and effectiveness of nutrition interventions in adult males - a guide for intervention strategies. Int J Behav Nutr Phys Act 10, 13-27. [Medline] [CrossRef]

10) Gu JK, Charles LE, Burchfiel CM, Fekedulegn D, Sarkisian K, Andrew ME, Ma C, Violanti JM (2012) Long work hours and adiposity among police officers in a US northeast city. J Occup Environ Med 54, 1374-81. [Medline] [CrossRef]

11) Violanti JM, Fekedulegn D, Hartley TA, Andrew ME, Charles LE, Mnatsakanova A, Burchfiel CM (2006) Police trauma and cardiovascular disease: association between PTSD symptoms and metabolic syndrome. Int J Emerg Ment Health 8, 227-37. [Medline]

12) Hannerz H, Albertsen K, Nielsen ML, Tuchsen F, Burr $\mathrm{H}$ (2004) Occupational factors and 5-year weight change among men in a danish national cohort. Health Psychol 23, 283-8. [Medline] [CrossRef]

13) Adams J, White M (2009) Time perspective in socioeconomic inequalities in smoking and body mass index. Health Psychol 28, 83-90. [Medline] [CrossRef]

14) Berge JM, Wickel K, Doherty WJ (2012) The individual and combined influence of the "quality" and "quantity" of family meals on adult body mass index. Fam Syst Health 30, 344-51. [Medline] [CrossRef]

15) Markey CN, Markey PM, Birch LL (2001) Interpersonal predictors of dieting practices among married couples. J Fam Psychol 15, 464-75. [Medline] [CrossRef]

16) Meltzer AL, McNulty JK, Karney BR (2012) Social support and weight maintenance in marriage: the interactive effects of support seeking, support provision, and gender. J Fam Psychol 26, 678-87. [Medline] [CrossRef]

17) Leatherdale ST, Laxer RE (2013) Reliability and validity of the weight status and dietary intake measures in the 
COMPASS questionnaire: are the self-reported measures of body mass index (BMI) and Canada's food guide servings robust? Int J Behav Nutr Phys Act 10, 42-54. [Medline] [CrossRef]

18) Cusatis DC, Shannon BM (1996) Influences on adolescent eating behavior. J Adolesc Health 18, 27-34. [Medline] [CrossRef]

19) Chen K, Scheier LM, Kandel DB (1996) Effects of chronic cocaine use on physical health: a prospective study in a general population sample. Drug Alcohol Depend 43, 23-37. [Medline] [CrossRef]
20) Procidano ME, Heller K (1983) Measures of perceived social support from friends and from family: three validation studies. Am J Community Psychol 11, 1-24. [Medline] [CrossRef]

21) Van Hasselt VB, Sheehan DC, Malcolm AS, Sellers AH, Baker MT, Couwels J (2008) The Law Enforcement Officer Stress Survey (LEOSS): evaluation of psychometric properties. Behav Modif 32, 133-51. [Medline] [CrossRef]

22) Khan A, Rayner GD (2003) Robustness to non-normality of common tests for the many-sample location problems. J Appl Math Decis Sci 7, 187-206. [CrossRef] 